\title{
A Teoria Dinâmica do Conhecimento de Duhem: um Termo Médio Entre a Concepçáo Metafísica Clássica da Ciência e a Concepçáo do Convencionalismo/Pragmatismo (Poincaré)
}

\author{
J. R. N. CHIAPPIN ${ }^{I}$
}

\begin{abstract}
RESUMO: O objetivo é propor uma reconstrução racional da concepção da ciência de Duhem, por meio do recurso da metodologia da teoria da ciência, como uma teoria normativa da dinâmica do conhecimento. Essa reconstrução ajuda a estabelecer que Duhem não pode ser classificado como um convencionalista/pragmatista, como sugere a interpretação-padrão, e, além disso, que Duhem almeja construir uma concepção que seja um termo médio entre a concepção metafísica clássica e a concepção do convencionalismo/pragmatismo. A estratégia metodológica para construir esse termo médio é a proposta de um realismo estrutural e convergente. Duhem substitui o sujeito transcendental dos clássicos por uma teoria transcendental a ser alcançada por um processo dinâmico.
\end{abstract}

PALAVRAS-CHAVE: Metodologia da teoria da ciência. Teoria dinâmica do conhecimento. Duhem. Poincaré. Realismo estrutural e convergente.

O objetivo deste artigo é realizar uma reconstrução racional da concepçáo da ciência de Duhem como uma teoria dinâmica de natureza convencional e normativa. As quatro teses centrais deste texto são: a primeira, que Duhem elabora uma concepção de teoria física de tal modo a demarcá-la, por um lado, da concepçáo clássica da ciência, tanto metafísica como empirista, e, por outro lado, da concepção convencionalista/pragmatista/instrumentalista de Poincaré; a segunda tese afirma que a demarcaçáo com respeito à concepção clássica é conduzida pela pressuposição de uma nova tese epistemológica para a qual o indivíduo racional é falível em lugar do sujeito transcendental dos clássicos; a terceira é uma tese ontológica, pela qual Duhem defende a existência de uma teoria transcendental, a teoria ideal, que descreve a estrutura real em que as leis empíricas são classificadas e ordenadas. Por conseguinte, a

\footnotetext{
${ }^{1}$ Professor Associado do Departamento de Economia da Universidade de São Paulo (FEA-USP). Graduado, Mestre e Doutor em Física, Instituto de Física-USP. Graduado em Filosofia, Departamento de Filosofia - USP. Master e Ph.D em Filosofia, University of Pittsburg. Doutor em Economia, Departamento de Economia, USP. Graduado em Direito, PUC-SP.
} 
terceira tese sustenta que Duhem defende um realismo metafísico que denominei realismo estrutural e convergente (CHIAPPIN, 1989, seção 3.8). E, finalmente, a quarta tese argumenta que o conhecimento científico é dinâmico segundo uma teoria da convergência à verdade, a qual se confunde com a tese transcendental de uma teoria ideal.

A presente reconstrução pretende ser particularmente uma resposta àqueles que interpretaram a concepção de Duhem como semelhante, interpretação-padrão, à de Poincaré, portanto, como convencionalista/instrumentalista. De acordo com essa concepção, a teoria física tem por objetivo e estrutura apenas representar matematicamente as leis físicas e, portanto, com valores exclusivamente instrumentais (CARTWRIGHT, 1983, p. 76-77, 87-99; VAN FRAASSEN, 1980, p. 2, 34-36, 86; GIEDYMIN, 1982; WORRAL, 1982; HESSE, 1980, p.208).

O foco principal do texto é reconstruir a estratégia por parte de Duhem para elaborar a concepção da teoria física como física teórica que a separe da concepção metafísica, mas, principalmente, que a demarque fundamentalmente da concepção convencionalista/instrumentalista/pragmatista de Poincaré. Essa estratégia leva Duhem a um realismo metafísico, embora de natureza diferente da concepção metafísica clássica da ciência.

Dessa forma, a concepção de Duhem se caracteriza como um termo médio entre a concepção metafísica clássica da ciência e a concepçáo convencionalista/pragmatista de Poincaré. Se, por um lado, ele rejeita o realismo fundacionalista do racionalismo clássico, por outro, não é para aproximar-se dos convencionalistas/pragmatistas com os quais partilha a demarcação relativamente à concepção metafísica clássica. A estratégia de Duhem para elaborar uma concepção como um termo médio é bastante sofisticada, já que rejeita a concepção metafísica clássica da ciência, embora mantendo sua adesão a alguns valores do racionalismo clássico e, ao mesmo tempo, ajustando-os às novas características epistemológicas e metodológicas da ciência moderna, a qual incorpora elementos convencionalistas/pragmatistas.

O elemento central da resposta à interpretação-padrão, Duhem como convencionalista/pragmatista/instrumentalista, a ser exposta neste texto, encontra-se desenvolvido extensivamente na minha tese de doutoramento defendida na Universidade de Pittsburgh, em março de 1989 (CHIAPPIN, 1989). Na tese, respondi diretamente à interpretação-padrão, particularmente a Worral, para quem, “[t]anto Duhem como Poincaré eram definitivamente 
instrumentalistas nos meus termos" (WORRAL, 1982). Nesse trabalho, argumentei explicitamente que Duhem construiu uma concepção da teoria física como um termo médio entre a concepção metafísica clássica e a concepção convencionalista/pragmatista.

A estratégia principal articulada para sua demarcaçáo do convencionalismo/pragmatismo de Poincaré focava na elaboração, de natureza metafísica, de uma concepção realista da ciência que denominei realismo estrutural e convergente (CHIAPPIN, 1989), exemplificando que a abordagem de Arnold da mecânica, para a qual a estrutura da mecânica hamiltoniana contém a mecânica lagrangeana, que, por sua vez, contém a mecânica newtoniana vetorial, seria um modelo desse realismo estrutural e convergente (CHIAPPIN, 1989, cap. 2).

Sustentei, na tese, que a proposta de Duhem explorava um termo médio o qual envolvia a combinação entre a concepção metafísica clássica e a concepçáo convencionalista/pragmatista com a proposta de um realismo estrutura e convergente (CHIAPPIN, 1989). Worral se tornou muito conhecido por defender a noção de realismo estrutural, em seu artigo "Structural Realism: the best of two worlds", publicado na revista Dialectica, em junho de 1989. Contudo, em 1982, enfatizava que ambos - Duhem e Poincaré - eram instrumentalistas. Esse artigo foi meu ponto de partida para estabelecer que Duhem era um realista e, mais, um realista estrutural. O irônico é que defendi a tese, em março de 1989, enquanto Worral publica esse seu famoso artigo em junho de 1989, sustentando a mesma posição da minha tese. Porém, Thomas Meier entende que "Worral's approach (WORRAL, 1989) is the locus classicus to the debate on structural realism". Minha posição, na tese de doutorado, foi sempre de que não há tal tipo de realismo consistente com a metodologia de Poincaré, mas, se existisse, seria um realismo ad hoc que náo se acopla com sua metodologia. O realismo estrutural é uma construção longa, detalhada e profunda da concepção de Duhem, visto que envolve todos os aspectos da sua filosofia, inclusive uma extensiva análise para refutar o realismo trazido pela teoria da matéria,aplicada por Poincaré, via mecanismo de massas em movimento, na mecânica, a qual, para Duhem, era também fonte da subdeterminação da mecânica pelos dados, e, do ceticismo

Além disso, no desdobramento deste artigo, não há também como polemizar ou nos opor também à concepção de Ernan McMullin sobre Duhem, porque o título do artigo por ele publicado - "Comment: Duhem's middle way" (MCMULLIN, 1990) -, de que a concepção de Duhem é um termo médio entre o convencionalismo de Poincaré e a concepção metafísica da ci- 
ência, é exatamente o tema, estabelecido de modo explícito, e a organização da tese de doutoramento (CHIAPPIN, 1989) apresentada na Universidade de Pittsburg, com a argumentação, do termo médio, sendo desenvolvida ao longo de todo o texto, a fim de reconstruir o realismo estrutural e convergente de Duhem (CHIAPPIN, 1989, cap. 3).

A reconstrução racional da teoria da ciência de Duhem é feita segundo um método que chamei de metodologia da teoria da ciência (MTC), composto por três níveis distintos, mas interconexos: metafísica, lógica da ciência e história da ciência. Ele está descrito tanto na tese de doutorado (CHIAPPIN, 1989) quanto em outro lugar (CHIAPPIN, 1996).

De modo sintético, a metodologia da teoria da ciência (MTC) compôe-se do nível metafísico, que contém teses ontológicas, epistemológicas e axiológicas desempenhando o papel de restriçóes e moldura de enquadramento relativamente às quais o autor busca construir e resolver seus problemas filosóficos; do nível da lógica da ciência, dividido, por sua vez, em dois subníveis formados da metametodologia, onde estáo localizados os argumentos e estratégias para o debate com as teorias rivais; e do nível metodológico, no qual estão descritos os métodos, modelos e técnicas para construir e resolver os problemas. Finalmente, há o nível da história da ciência, no qual se encontram tanto a filosofia da história do autor quanto o papel metodológico atribuído à história da ciência, na sua concepção de ciência.

O resultado da reconstrução racional da concepção da teoria física de Duhem é uma teoria dinâmica do crescimento científico, que define o crescimento do conhecimento como contínuo e racional, e que estrategicamente a demarca, como um termo médio, por um lado, da concepção clássica da ciência, metafísica e empirista, e, por outro, da concepção convencionalista/ pragmatista de Poincaré.

Assim como Duhem, a concepção da teoria física de Poincaré foi elaborada para demarcá-la radicalmente da concepção metafísica da ciência. Mas seus tons céticos, provenientes de sua prática científica, a qual convivia com grandes indeterminaçóes emergentes na física, principalmente mecanicista, como a teoria do caos, de sua autoria, eliminaram da concepção da ciência quaisquer pretensóes de atribuir à ciência algum estatuto cognitivo de valor de conhecimento ou valor objetivo, acabando por reduzi-la a um valor puramente instrumental e prático, que o próprio Poincaré defendia com base em seu valor heurístico, o que provocou a reação de Duhem. 
A concepção metafísica da teoria física está fortemente associada ao racionalismo clássico e ao mecanicismo dogmático. $\mathrm{Na}$ visão de Duhem, a concepção clássica confunde metafísica e física, quando afirma que o objeto da teoria física é proporcionar uma explicação causal dos fenômenos físicos, a qual consiste em buscar as causas físicas dos fenômenos. Duhem declara explicitamente que sua proposta de teoria física não adota semelhante tradição:

\begin{abstract}
Pode-se considerar a física teórica ao modo dos cartesianos e dos atomistas em que os corpos que os sentidos e os instrumentos percebem são divididos em corpos imensamente numerosos e muito menores que somente a razão pode conhecer; os movimentos que se observa, por sua vez, são considerados como os efeitos resultantes dos movimentos imperceptíveis destes pequenos corpos; a estes corpos atribuem-se formas pouco numerosas e bem definidas. A partir de seus movimentos, formulam-se leis muito simples e inteiramente gerais. Estes corpos, estes movimentos são, de fato, os únicos corpos reais, os únicos movimentos reais. Quando reunidos de maneira conveniente, sendo reconhecidos como capazes de produzir coletivamente efeitos similares aos fenômenos que observamos, declara-se que se descobriu uma explicação destes fenômenos. Não é assim que procede nossa energética. (DUHEM, 1917, p. 151).
\end{abstract}

A tese epistemológica central da concepção metafísica é que há um sujeito transcendental, cujo modelo é o cogito (DESCARTES, 1973), que possui todas as condiçôes epistêmicas para apreender os princípios reais e causais dos fenômenos físicos. A intuição intelectual é a faculdade de apreender os princípios causais e autoevidentes da física. Os critérios de verdade são clareza e distinção. A física teórica é organizada numa concepção axiomática ideal, constituída de ideias simples e princípios autoevidentes, seguindo o modelo geométrico. As pressuposiçôes básicas são verdadeiras e, quando universais, obtêm-se delas, pelo método dedutivo, interpretado como um conjunto de intuiçóes, as demais proposiçóes verdadeiras, derivadas ou construídas do sistema. Tem-se aqui uma teoria da cascata da verdade. Quando as pressuposiçôes básicas verdadeiras são proposiçóes empíricas particulares, o processo da cascata é o inverso e o método é o método indutivo.

A teoria da cascata da verdade (CHIAPPIN, 1996) procura resolver o problema de como é possível, numa organização axiomática, em que os primeiros princípios são proposiçóes verdadeiras e autoevidentes, podermos tratar de crescimento do conhecimento. A solução de Descartes é epistemológica, reduzindo a dedução a um conjunto de intuiçôes do sujeito, portanto, a noção 
de crescimento no quadro do conhecimento certo é dependente do sujeito transcendental. A solução do crescimento está na ideia ontológica e epistemológica de que o sujeito possui acesso às essências e, pois, pode conhecer as verdades dos pressupostos básicos da ciência. Só desse modo se pode organizar geometricamente o conhecimento e ainda falar em crescimento.

A tese ontológica central acerca da natureza é que as coisas reais são mecânicas. O movimento e as massas invisíveis com as propriedades da extensão e tamanho são considerados princípios causais de todos os fenômenos físicos. A matemática e a geometria fornecem a linguagem e a moldura com as quais a mecânica deve ser formulada. A epistemologia e a metodologia da física mecanicista são então ajustadas a esse modelo matemático-geométrico.

O método para construir a teoria física é o método mecânico, que faz construçóes das explicaçóes de fenômenos físicos, por meio da construção de modelos formados por massas invisíveis em movimento. Contudo, a teoria física deve ser organizada segundo o procedimento dedutivo ao estilo da geometria, o qual é o modelo fundamental da ciência. Duhem chama esse método de construção de método metafísico (DUHEM, 1980, p. 98). O método crítico para avaliar hipóteses físicas rivais é o método experimental, juntamente com as condições impostas pela base conceitual. $\mathrm{O}$ método experimental funciona à imagem e semelhança ao método de redução ao absurdo da matemática, por conseguinte, como método de prova, podendo assim ser associado a um experimento crucial, decidindo tanto pela verdade como pela falsidade.

Ao comentar a origem dessa interpretação, Duhem (1974, p. 185) observa que ela "[...] é copiada da redução ao absurdo; a contradição experimental exercendo o mesmo papel em uma [na física], que a contradição lógica exerce na outra [na geometria]".

Porém, Duhem é mais radical, porque pretende igualmente que sua concepção da teoria física não só a demarque da concepção metafísica, mas também que a demarque da concepção empirista, tal como Newton a construiu, no racionalismo clássico. Duhem quer essa demarcação da concepção empirista, pois seu objetivo é elaborar uma concepção da teoria física como física teórica e náo como física experimental, e o empirismo e o indutivismo a ele associados lhe parecem incompatíveis com a natureza da física teórica.

A concepção empirista clássica, com o método indutivo como método de construção de teorias físicas, é incorporada em parte pelo pragmatismo moderno. Todavia, este último, com Poincaré, rompe com duas teses centrais 
da concepção clássica (o princípio da unidade lógica - PUL - e a interpretação clássica do método experimental), além de adotar o método de construção de modelos do mecanicismo moderno. A concepção empirista/indutivista toma a ciência empírica como o modelo para a física teórica, fazendo com que esta última acabe, assim, identificada com a física experimental. Duhem formula com clareza seu desejo de demarcar sua proposta dessa concepção:

Pode-se conceber a física teórica ao modo dos newtonianos. Rejeitam-se todas as hipóteses sobre os corpos imperceptíveis e sobre os movimentos ocultos, dos quais poderiam ser compostos os corpos e os movimentos apreendidos pelos sentidos e pelos instrumentos. Os únicos princípios que se admitem são as leis muito gerais conhecidas por indução a partir da observação dos fatos. Nossa energética não segue o método newtoniano. (DUHEM, 1917, p. 151-152).

A epistemologia e a metodologia dessa concepção empirista clássica são quase as mesmas dos intelectualistas do racionalismo clássico, exceto que, em lugar de uma base apriorística, formada de proposiçóes universais, a substituem por uma base empírica constituída de proposiçóes particulares, sustentada por uma epistemologia para a qual as proposiçóes observacionais básicas são consideradas verdadeiras e obtidas pela intuição sensível como a faculdade do conhecimento no lugar do entendimento (DUHEM, 1974, p. 330). A teoria do progresso é, assim, uma teoria da cascata invertida e associada com o acúmulo de proposiçóes verdadeiras, semelhante ao progresso em matemática.

Essa ideia de progresso da concepção empirista se deve à interpretação do método experimental como um método de prova e de que as pressuposiçóes básicas da ciência são princípios autoevidentes, bem como ao princípio da separabilidade e testabilidade das proposiçóes isoladas como instrumentos de avaliação crítica das hipóteses. Esse princípio afirma que as proposições científicas podem ser separadas e submetidas a teste de modo independente. Essa é a regra metodológica central subjacente ao método indutivo, a qual será duramente criticada por Duhem, que vai substituí-la pela D-thesis ou a tese de Duhem, segundo a qual nunca testamos hipóteses isoladas, mas a teoria como um tudo.

A análise epistemológica das proposiçóes científicas, como faz Hume, e a história do desenvolvimento científico apontam tanto para a emergência de novos domínios científicos autônomos (como a termodinâmica e o eletromagnetismo, os quais se mostravam refratários às reduçóes mecânicas) quanto para 
a refutação e rejeição de teorias físicas anteriormente aceitas como verdadeiras (como é o caso da teoria do calórico). Nesse contexto, não há como defender a tese de que o indivíduo é transcendental com acesso às essências e a tese de que há conhecimento certo, pois a análise epistemológica do método científico e o estudo do desenvolvimento científico ressaltam que a natureza do conhecimento científico está no seu caráter hipotético e, portanto, que o ponto de partida do conhecimento é a falibilidade do indivíduo racional.

Com essas duas críticas à concepção clássica da ciência, Duhem busca reavaliar criticamente a concepçáo clássica e propor uma nova reflexão sobre o fundamento, a natureza, o objeto e a estrutura da teoria da física, a qual se constitua em um novo programa racionalista, o programa racionalista neoclássico, em substituição ao programa racionalista clássico (CHIAPPIN; LEISTER, 2011), adotando a tese fundamental de que o conhecimento tem caráter hipotético-dedutivo e de certeza.

Como ponto de partida desse empreendimento, Duhem enfatiza, em franca oposiçãa à concepçáo clássica e sua teoria do progresso:

As teorias físicas não progridem como as teorias matemáticas, pela contínua introdução de novas proposiçóes, definitivamente demonstradas, que se unem a proposiçōes já reconhecidas como certas. (DUHEM, 1895a, p. 27).

Duhem rejeita, nessa passagem, que conhecimento é conhecimento certo ou provado ou, como ele mesmo destaca, definitivamente demonstrado, e que, portanto, as teorias físicas progridem por meio da acumulação dessas proposiçóes definitivamente provadas. Esse posicionamento epistemológico de Duhem é bastante semelhante (CHIAPPIN; LEISTER, 2013) àqueles adotados, mais tarde, por Popper (1963), Kuhn (1992) e Lakatos (1970). Lakatos, comentando a concepção epistemológica de Popper e Kuhn, afirma que o ponto de partida de suas concepçóes é relativo à reação deles à concepção clássica de progresso, segundo a qual "[...] por séculos conhecimento significou conhecimento provado - provado pelo poder do intelecto ou pela evidência dos sentidos" (LAKATOS, 1970). Salienta Lakatos:

Kuhn pensa de modo diferente. Ele também rejeita a ideia que a ciência cresce por acumulação de verdades eternas. Ele também toma como sua principal inspiração a substituição da física Newtoniana pela de Einstein. Seu problema é também a revoluçáo científica. Mas, enquanto de acordo com Popper ciência é "revolução permanentemente" crítica do núcleo do empreendimento científico, 
de acordo com Kuhn, revolução é algo excepcional, e, mesmo, extra científico, e, a crítica é, em tempos "normais", um anátema. (LAKATOS, 1970, p. 92).

A introdução desse fragmento de Lakatos, neste ponto, é apenas para apontar que os três autores mencionados são prolíficos em passagens, estruturas e raciocínios muito semelhantes àqueles de Duhem, na abordagem do problema de se construir uma nova concepção de epistemologia e metodologia da ciência proveniente da consolidação, pelo avanço da ciência e pelas análises epistemológicas, de que a natureza do conhecimento científico é hipotética e não conhecimento demonstrado.

Duhem está junto com Poincaré na construção de um novo programa racionalista para resolver as dificuldades do programa do racionalismo clássico quanto aos novos problemas do conhecimento científico. O programa do racionalismo neoclássico, com Duhem e Poincaré, tenta construir uma nova epistemologia, axiologia e metodologia, e, sobretudo, um novo modelo de racionalidade, mais adaptados às novas características da ciência moderna relacionadas com seu caráter hipotético-dedutivo, com a emergência de novas áreas do conhecimento, como termodinâmica e eletromagnetismo, que relutavam em ter explicaçôes mecânicas, com novos instrumentos matemáticos, como mecânica analítica, sistemas dinâmicos, novas geometrias e estatística aplicada à mecânica..

A concepção da ciência que Duhem desenvolve, guiado pela ideia reguladora de um termo médio (middle way), de inspiração kantiana, entre as concepções metafísica e pragmatista/convencionalista da física teórica, não busca, contudo, como acontece com Poincaré, uma ruptura radical com a tradição do racionalismo clássico, tanto da concepção intelectualista quanto da concepção empirista. Duhem se opóe a rupturas radicais e revoluçôes, quer em epistemologia, quer em ciência. Ele defende uma concepção de história e, portanto, de progresso científico continuísta sem rupturas.

A estratégia de Duhem seguindo a ideia reguladora do termo médio é, desse modo, começar a partir de um resgate crítico dessas duas tradiçôes quanto à concepção de ciência do racionalismo clássico, que consiste da concepção metafísica (Descartes) e da concepção empirista (Locke e Newton), a fim de desenvolver uma síntese, como já tinha sido tentada por Kant, entre o empirismo e o intelectualismo do racionalismo clássico, com o despertar, graças a Hume, do sonho dogmático. 
O projeto kantiano desenvolveu uma síntese entre o intelectualismo e o empirismo do racionalismo clássico fundado em uma proposta de interpretar as proposiçóes da ciência como juízos sintéticos a priori, em lugar, como interpretava Hume, de juízos sintéticos, e interpretar, como consequência, a Mecânica de Newton como uma teoria verdadeira. Com os juízos sintéticos $a$ priori, Kant proporciona um fundamento teórico para as proposiçóes conhecidas como certas de Descartes e consideradas como componentes genuínos da teoria da ciência. Contudo, o recurso a juízos sintéticos a priori trouxe dificuldades e controvérsias para uma explicaçáo kantiana da dinâmica do progresso e desenvolvimento científico, envolvendo teorias cada vez mais abrangentes e processos de avaliação de teorias, com rejeição de teorias refutadas como falsas pelo teste experimental. As dificuldades, problemas e controvérsias relacionadas com a teoria kantiana dos fundamentos da ciência estimularam novas propostas, como o programa do racionalismo neoclássico (CHIAPPIN; LEISTER, 2011) e, em particular, a teoria da dinâmica da ciência de Duhem.

$\mathrm{Na}$ construção da concepção da teoria física como termo médio, um dos princípios que organiza sua teorização científica é o da autonomia da física, que deve ser sustentada por seus próprios métodos. No caso de Descartes, a aplicação do princípio da autonomia requereu uma concepção de ciência a qual proporcionasse uma demarcação entre ciência (metafísica e física) e religiấo. No caso de Duhem, entretanto, tal princípio requer a demarcação entre metafísica e física teórica, mas também entre física teórica e física experimental (de base empirista).

A crítica da relação de dependência da física à metafísica, como entendia Descartes, é feita, por Duhem, sob a orientação da tradição aristotélica, a qual legitima diferentes objetos e métodos do conhecimento científico e, com esse recurso, permite que Duhem rejeite a concepçáo positivista de que o método da física é o único método do conhecimento e, por aqui, se oponha à concepção pragmatista/empirista/convencionalista que concebia a metafísica como um pseudoconhecimento. Duhem afirma:

É, com efeito, uma das grandes razóes para a fama da filosofia de Aristóteles haver reconhecido que cada ciência possuía seu domínio próprio e seus métodos independentes, e que a harmonia não exigia a confusão - pelo contrário. (DUHEM, 1893a, p. 123). 
O recurso à proposta de Aristóteles torna possível aludir a diferentes domínios de conhecimento. Ela possibilita operar sua proposta de demarcação como estratégica, principalmente, para marcar, por meio da preservação da metafísica, seu distanciamento com a concepção convencionalista/pragmatista de Poincaré e seus tons céticos acerca do conhecimento. Um dos críticos de Duhem argumenta, contudo, que sua demarcação tem por fonte seu desdém pela metafísica, ao destacar que "[...] não é por amor à metafísica [...] que Duhem lhe deixa o campo livre; é, sobretudo, por desdém” (DUHEM, 1893a, p. 123). Duhem responde salientando que a importância dessa sua demarcação não é para destruir a metafísica, mas, ao contrário, para redefinir a função que a metafísica deve exercer com respeito à física:

Peço desculpas a meu sábio contraditor, mas acredito que ele náo me compreendeu; buscando marcar a separação entre a ciência positiva e a metafísica, não pretendo desdenhar nem uma, nem outra destas duas ciências, e penso em facilitar seu acordo, muito mais que se confundisse o objeto e o método de uma com o objeto e o método da outra. (DUHEM, 1893a, p. 123).

Dessa forma, Duhem, se, por um lado, rejeita a metafísica como fundamento da ciência (DUHEM, 1980, p.98), como quer Descartes (1973), por outro, de modo algum pretendeu colocar-se ao lado e fazer a crítica nos mesmos termos de seus contemporâneos positivistas, pregando a destruição da metafísica como pseudoconhecimento. Segundo Duhem, a metafísica e a física seriam, com as categorias aristotélicas, dois domínios distintos, construindo formas diferentes de conhecimento, com seus próprios métodos e objetivos - e não, como querem alguns positivistas, como Comte, com sua lei dos três estágios - teologia, metafísica e ciência - num processo histórico, por superação, em direção ao desenvolvimento científico.

A metafísica rejeitada como fundamento da ciência passa a ter, na teoria da ciência de Duhem, uma dupla função: (1) iluminar a relação entre os princípios que guiam nossa razão, para formular e legitimar a concepção de teoria física e para descrever o crescimento do conhecimento científico; e (2) desempenhar um importante papel para evitar o ceticismo. Duhem é explícito sobre essas duas funções da metafísica:

Confinada em seu forte, ela [a teoria física] só pode temer dois tipos de adversários: os fisicos que a contestam, seja em nome da experiência, seja em nome de outras teorias físicas, e os céticos que negam a evidência e a certeza de qualquer uma das noçôes, de qualquer um dos princípios sobre os quais 
repousam logicamente a ciência experimental; quanto aos últimos, a física não possui competência para combatê-los; ela não está armada para tanto; cabe à metafísica mostrar que os fundamentos do método experimental são sólidos; o físico deve admitir esta verdade como evidente; sobre o terreno próprio destas teorias, o físico não pode e não deve aceitar o combate senáo com o físico. (DUHEM, 1893b, p. 68, grifos meus).

O conteúdo dos enunciados metafísicos, no entender de Duhem, não são formas a priori de nosso conhecimento, ou seja, juízos sintéticos a priori. Ao invés disso, são valores que resultam de certa força intuitiva e são expressos em termos de comandos com a função normativa de orientação ao comportamento do cientista. Duhem usa o espaço da metafísica para estabelecer um conjunto de regras, princípios e normas que denomino teses ontológicas, epistemológicas e axiológicas, as quais formam um quadro teórico, uma metafísica do conhecimento, para servir de orientação para os cientistas na construção de uma concepçáo da ciência comprometida com a verdade e que seja um meio termo (middle way) entre a concepção metafísica, fundamento da física tanto na versão intelectualista quanto empirista do racionalismo clássico, e a concepção positivista, particularmente de Poincaré, que rejeita a metafísica como pseudoconhecimento e também o valor de conhecimento da ciência.

Com o pressuposto de que há um papel importante para a metafísica relativamente à física, pode-se assumir com Duhem, inicialmente, um tipo de metafísica fideísta, formada de princípios ou ideias reguladoras do domínio auxiliar na construção da sua concepção de ciência. Ela serve para iluminar as relaçôes entre os princípios que guiam nossa razão e, especialmente, no seu combate ao ceticismo e à redução da ciência a um valor puramente instrumental e prático. Assim, ela é estratégica na sua crítica da concepção convencionalista/pragmatista de Poincaré.

Duhem relembra esse papel da metafísica com relação à física, ao observar a importância de se aplicar na teoria física o princípio da unidade lógica (PUL), ao invés do princípio da subdeterminação da teoria pelos dados (PSTD), dois princípios que determinam a diferença entre ele e Poincaré:

Mas embora esta verdade [PUL] seja tão clara e tão evidente que todo físico de fato a usa sem hesitar ao longo de suas pesquisas, disto não resulta que o metafísico não tenha que dar conta da mesma, não para ampliar a clareza, que é completa, ou a certeza, que é intuitiva, mas para nos permitir conhecer as relaçóes deste princípio com outros princípios que guiam 
nossa razão, e para desarmar o ceticismo, se ele pretender minar este fundamento da física teórica. (DUHEM, 1893c, p. 368).

Estabelecida a demarcação com a concepção metafísica clássica e preservada a metafísica com suas novas funções, o principal desafio é a demarcação com a concepção de Poincaré, mantendo, contudo, o compartilhamento, por ambos, que é hipotético-dedutivo, a propósito da nova natureza do conhecimento científico.

O estado inicial do conhecimento a respeito do mundo dado pela física é, assim, um conhecimento produzido pelo indivíduo racional, mas sujeito às restriçôes epistemológicas. A falibilidade do sujeito é uma das teses epistemológicas de Duhem, com a qual rejeita o sujeito transcendental do racionalismo clássico e substitui o conhecimento certo pelo conhecimento hipotético:

A inteligência do homem não possui conhecimento direto, a visão imediata da essência das coisas exteriores; o que conhecemos diretamente destas coisas são os fenômenos dos quais elas são o assento e a sucessão. (DUHEM, 1893b, p. 57).

Completa-se a tese da falibilidade com a tese de que o conhecimento é adquirido empiricamente por meio de um método experimental limitado ao conhecimento dos fenômenos, conforme o autor ressalta:

O método experimental, o único a que podemos recorrer para este objetivo [a classificação das leis físicas], que não apreende a essência das coisas, mas apenas os fenômenos através dos quais as coisas se manifestam a nós, não nos permite aproximar as leis umas das outras, senão por analogias exteriores, superficiais, que traduzem, traindo-as talvez constantemente, as verdadeiras afinidades das essências das quais as leis emanam. (DUHEM, 1893c, p. 369).

Ambas as teses epistemológicas são formuladas em oposição aos pressupostos epistemológicos da concepção metafísica da teoria física, a qual construiu um sujeito transcendental com acesso direto às essências. Elas também criam os contornos para a nova moldura epistemológica do racionalismo neoclássico, que Duhem está ajudando a construir, em substituição ao racionalismo clássico, já discutido em outro lugar (CHIAPPIN; LEISTER, 2011). 
Se há, no contexto do conhecimento humano direto, limitaçóes epistemológicas com a falibilidade do indivíduo, no conhecimento indireto existem, todavia, meios de aperfeiçoar sistematicamente esse conhecimento, que começaria com a adoção do método experimental. Duhem enriquece sua metafísica do conhecimento com outras ideias reguladoras para compor uma estratégia para a superação dessas limitações epistemológicas do conhecimento que nossas faculdades permitem, em termos diretos. A principal ideia reguladora da estratégia da teoria da ciência de Duhem pode ser denominada, como faz Popper, tese suprema de sua metafísica do conhecimento, e versa sobre a busca do conhecimento.

A tese suprema de Duhem estabelece a ideia reguladora, como um comando, de que o cientista deve buscar um aperfeiçoamento sistemático da teoria física, apesar das imperfeiçôes dos nossos meios de conhecimento: "Por mais imperfeitas que sejam nossas teorias físicas, elas podem e devem tender ao perfeito" (DUHEM, 1893c, p. 369).

A consequência direta da tese suprema é caracterizar a atividade científica, exercida por meio do método experimental que fornece apenas hipóteses, por meio de uma teoria dinâmica voltada para implementar o desenvolvimento científico, e também que a natureza dessa teoria dinâmica é de ser resultado de um procedimento normativo. Ela está comprometida com uma visão crítica e não dogmática da ciência. Como toda teoria normativa, ela deve se constituir em um conjunto de procedimentos visando à realização de certos valores e fins e, pois, formada de elementos extralógicos e extraempíricos, ou seja, metafísicos.

Na metafísica do conhecimento de Duhem, chamamos de axiologia o conjunto de teses de valores e fins que Duhem propôs que uma concepção da ciência deve possuir e buscar realizar, em particular, que a dinâmica do conhecimento científico deve ser conduzida de tal modo a buscar uma teoria que represente a natureza física tal como ela é. Trata-se de uma teoria transcendental em substituição ao sujeito transcendental (DESCARTES, 1973), a qual representa seu compromisso com o valor do racionalismo clássico de que a teoria física deve sempre buscar a verdade. Em oposição a este último, a verdade, agora, não mais se encontra no alcance direito do sujeito, mas por meio indireto, no sentido de uma ascensão metódica. Assim, os compromissos ontológicos de Duhem a respeito das características do mundo exterior, que pretendemos conhecer por meio das teorias físicas, devem preceder sua axiologia. 
Segundo Duhem, há ao menos duas coisas que podemos afirmar, ontologicamente, sobre esse mundo exterior: que este não é indeterminado nem contraditório. Duhem enfatiza:

Se sabemos poucas coisas acerca das relaçóes existentes entre as substâncias materiais, há ao menos duas verdades acerca das quais estamos seguros: que estas relaçóes náo sáo nem indeterminadas nem contraditórias. (DUHEM, 1893c, p. 369.).

Essa tese estabelece condiçôes mínimas para uma abordagem racional do conhecimento do mundo externo com importantes consequências na epistemologia e metodologia de Duhem, particularmente na elaboração de sua concepçáo para se contrapor à concepçáo convencionalista/pragmatista de Poincaré. Essa tese imporá, por meio de uma regra metodológico-epistemológica fundamental, a saber, TME, a aplicação do princípio da unidade lógica (PUL), em lugar do princípio da subdeterminação da teoria pelos dados (PSTD), que é a regra metodológica central e fonte do ceticismo e pragmatismo da concepção de Poincaré.

Uma tese adicional implementa e descreve ainda mais materialmente a tese transcendental da concepção de Duhem, por postular a existência de uma teoria física ideal e perfeita, que classificaria as leis em uma ordem natural. Segundo suas próprias palavras:

Esta [a teoria física ideal e perfeita] seria a explicação metafísica total e adequada da natureza das coisas materiais; esta teoria, com efeito, classificaria as leis físicas em uma ordem que seria a expressão mesma das relaçôes metafísicas existentes entre as essências das quais estas leis emanam; ela nos daria, no sentido próprio do termo, uma classificação natural das leis. (DUHEM, 1893c, p. 368).

Essa tese ontológica pode ser completada com outra, pela qual atribui, de modo explícito, o estatuto transcendental à teoria ideal. Ele destaca:

Tal teoria, como tudo que é perfeito, ultrapassa infinitamente a capacidade do espírito humano; as teorias que nossos métodos nos permitem construir são apenas um pálido reflexo. (DUHEM, 1893c, p. 369). 
Com a tese transcendental, Duhem substitui a do sujeito transcendental do racionalismo clássico, o cogito, que acessa diretamente as essências e torna possível o conhecimento certo, mantendo o compromisso de que a teoria física tem por objeto a verdade, ainda que não diretamente. $\mathrm{O}$ método de acesso a essa teoria transcendental é a dinâmica do conhecimento por um processo de ascensão sistemático e contínuo.

De acordo com a tese transcendental de Duhem sobre a teoria física ideal, a verdade não está mais no ponto de partida do conhecimento científico, como queriam os racionalistas clássicos, com a tese do sujeito transcendental, mas no ponto de chegada do desenvolvimento científico. A teoria científica não deve ser uma teoria estática, como descreve o modelo da cascata da verdade, porém, uma teoria dinâmica do conhecimento. Ela deve ter uma natureza normativa. Essa teoria normativa da dinâmica do conhecimento científico, segundo Duhem, tem que ser um modelo da convergência para a verdade (CHIAPPIN, 1989).

O conjunto dessas teses sobre a teoria ideal não expressa apenas restriçốes importantes na construção da teoria física, mas procedimentos, visto que estas servem para compor uma proposta normativa com a finalidade de determinar o comportamento que o cientista deve seguir, se estiver comprometido em procurar a verdade, que, no caso, consiste na busca da teoria física ideal. Segue-se que, se a construção da teoria física busca refletir a natureza do mundo e tenta se aproximar da teoria ideal, ela deverá evitar contradiçóes e indeterminaçôes.

Completando a metafísica do conhecimento de Duhem, temos seu posicionamento teórico quanto aos fins e valores, o domínio da axiologia, a que a construção da concepção da teoria física deve visar e que devem servir de orientação em seu desejo de desenvolvê-la como um termo médio (middle way) entre a concepção metafísica e a concepção convencionalista/pragmatista de Poincaré.

A axiologia (LAUDAN, 1984) de Duhem apresenta os objetivos, os fins e os valores que as concepçóes de física teórica devem supostamente realizar e com quem precisam estar comprometidas. Há duas teses axiológicas que expressam objetivos compatíveis ou extraídos de suas teses epistemológicas e ontológicas.

A primeira tese sublinha a já mencionada proposta da demarcação com respeito à metafísica. Em duas partes, ela sustenta o princípio da autonomia da 
ciência: a primeira parte estabelece que o objetivo da construção da concepção da teoria física é, primeiramente, demarcar a física teórica da metafísica intelectualista com sua proposta de fundamentação metafísica da física por derivação. Essa tese afirma o objetivo de tornar a física teórica autônoma com relação à metafísica. Ela é consequência direta de suas teses epistemológicas anteriores, as quais limitam nosso conhecimento ao conhecimento dos fenômenos. Duhem formula esse objetivo de maneira inequívoca, na seguinte passagem, "Cumpre, necessariamente, que a física possa se constituir através de um método próprio, independente de toda metafísica” (DUHEM, 1893b, p. 62).

A segunda parte procura não apenas demarcar a física teórica da metafísica, mas também a física teórica da física experimental. Duhem diferencia física teórica da física experimental, pois têm características epistemológicas diferentes. Na última, o método empírico é identificado com as inferências indutivas, enquanto a física teórica é identificada por Duhem com a física matemática (que é distinta da experimental). Duhem expressa tal demarcação, explicitamente: $\mathrm{O}$ conhecimento das leis experimentais constitui a ciência puramente experimental, tão acima do empirismo quanto a lei está acima do fato particular. Mas a ciência puramente experimental não é o último termo do conhecimento do mundo exterior. Acima dela está a ciência teórica. O que nos propomos a estudar é a natureza desta ciência, tomando como exemplo a teoria mais próxima da perfeição, aquela que recebeu o nome de fisica matemática. (DUHEM, 1892, p. 140, grifos meus).

Em conformidade com as restrições epistemológicas acima e buscando a realização expressa por essa axiologia, Duhem procura elaborar uma definição de teoria física que opere essas demarcaçóes, com ênfase nas características de uma física matemática. Duhem explica da seguinte forma sua proposta para a natureza da teoria física:

[A teoria física] é um sistema de proposiçóes matemáticas, deduzidas de um pequeno número de princípios que buscam representar, de maneira tão simples, completa e exata quanto possível, um conjunto de leis experimentais. (DUHEM, 1974, p. 19).

Tal definição de teoria física como um sistema que busca representar leis empíricas se baseia na ideia de representação matemática como uma relação simbólica entre conceitos físicos e propriedades físicas, e no uso da álgebra 
como a linguagem apropriada para expressar e manipular tais símbolos. Uma teoria física é uma representação matemática axiomática das leis experimentais, sem depender de modelos algébricos.

Nesse objetivo da demarcação com a metafísica, Duhem encontra-se em companhia de muito de seus contemporâneos, particularmente de Poincaré e Mach. A proposta de Poincaré é bastante semelhante à de Duhem, como podemos ver abaixo, na seguinte passagem:

O objetivo da teoria matemática náo é nos revelar a natureza real das coisas; esta seria uma exigência irrealizável. Seu único objetivo consiste em coordenar as leis físicas com as quais a experiência nos familiariza [...] (POINCARÉ, 1952, p. 211).

Desse modo, ambas as definições de Duhem e de Poincaré, sobre o objetivo da teoria física, são subdeterminadas com respeito à tarefa de demarcar física e metafísica. Elas definem a natureza da teoria física como representação matemática das leis experimentais, de sorte a realizar tal demarcação, evitando atribuir à teoria física o objetivo de oferecer explicaçóes causais.

Poincaré constrói sua definição de teoria física bastante bem ajustada aos resultados da física de seus contemporâneos e da sua própria, com inúmeros novos instrumentos, como a mecânica analítica (lagrangeana e hamiltoniana) e os sistemas dinâmicos que ele mesmo estava desenvolvendo. Este último instrumento teórico introduz novas indeterminações na física, como a propriedade da hipersensibilidade às condiçôes iniciais (caos) e múltiplas soluçóes. Ele dá boas vindas, ao contrário de Duhem, ao uso desses instrumentos, na física. A atividade científica de Poincaré com esses instrumentos são a fonte de ter admitido regras metodológicas as quais tornam ilegítimo reivindicar valor de conhecimento para uma teoria física, reduzindo-a a valores práticos e ao pragmatismo e convencionalismo. Ele ressalta:

Não devemos nos orgulhar de evitar toda contradição. Mas devemos tomar partido. Duas teorias contraditórias, com efeito, contanto que náo as misturemos, e nem busquemos a essência das coisas, podem ambas ser instrumentos úteis de pesquisa. Talvez a leitura de Maxwell fosse menos sugestiva se ela não tivesse aberto tantos caminhos novos, divergentes. (DUHEM, 1974, p. 91; POINCARÉ, 1901, p. vi). 
A segunda tese axiológica de Duhem tem como função estabelecer que, se sua concepção da teoria física partilha com Poincaré uma concepção de física que a demarque da metafísica, sua concepção igualmente se pretende demarcada e separada da concepção convencionalista/pragmatista de Poincaré.

A concepção de teoria física de Duhem está comprometida com os valores do racionalismo clássico, particularmente que a teoria física deve buscar a verdade, um valor de conhecimento, rejeitando as consequências céticas da concepção de Poincaré. As teses ontológicas, axiológicas e epistemológicas fazem parte de uma superestrutura metafísica a qual define o contorno da concepção da teoria física de Duhem como uma teoria normativa, antecipando a de Popper, que se propóe determinar o comportamento do cientista em seu compromisso com o antidogmatismo e, portanto, com o desenvolvimento científico.

Esse compromisso leva Duhem a elaborar uma teoria normativa da dinâmica do conhecimento cuja característica, para demarcá-la da concepção convencionalista/pragmatista de Poincaré, é a de ser uma teoria da convergência da verdade como um realismo estrutural, por rejeitar a teoria da matéria, e convergente, por estar comprometida com uma teoria transcendental alcançada por meio de uma dinâmica.

A teoria dinâmica do conhecimento é a estratégia de Duhem para compartilhar da demarcação com a concepção metafísica da ciência, sem destruir seu valor de conhecimento com o estabelecimento da tese da teoria transcendental.

Essa postura epistemológica e metodológica faz Poincaré substituir um dos princípios fortes da racionalidade clássica, o princípio da unidade lógica (PUL), pelo princípio da subdeterminação da teoria pelos dados (PSTD). Assim, não há uma única teoria para uma base empírica, mas infinitas, como seus estudos da mecânica lhe mostram, que, se há explicação formada de massas invisíveis em movimento, há então infinitas, resultantes da combinaçâo dos parâmetros massa e velocidade. Esse princípio pertence ao núcleo do seu programa metodológico da teoria física.

A regra da subdeterminação (RS), instrumento metodológico de Poincaré, estabelece que a física deve usar teorias distintas e incompatíveis (DUHEM, 1974, p. 330), corolário de uma tese mais forte formulada por Poincaré, que denomino princípio da subdeterminação das teorias pelos dados (PSTD), para o qual “[...] os mesmos fatos podem ser explicados por uma infinidade de teorias, igualmente verdadeiras, porque todas reproduzem os fatos a serem explicados" (PARETO, 1909, p. 31-36 apud LATSIS, 1976, p. 9). 
A consequência da aplicação do princípio da subdeterminação das teorias pelos dados (PSTD) é que o método experimental não pode nem verificar nem falsificar as teorias científicas, portanto, que não há experimentos cruciais capazes de decidir entre teorias físicas rivais. A aplicação da regra se dá de modo similar àquela da construção de massas invisíveis em movimento (POINCARÉ, 1891, p. 326; QUINN, 1969, p. 398).

Essa regra sintetiza a crítica de Poincaré aos dois princípios fundamentais do racionalismo clássico, o princípio da unidade lógica da teoria, o qual impede a presença de contradiçóes e incoerências na teoria física, e o princípio da testabilidade empírica, isto é, de que o método experimental é um método para produzir decisôes conclusivas sobre as proposições científicas, com a consequência de reduzir o valor da teoria física a valores instrumentais e práticos. O ceticismo emerge soberano na teoria física de Poincaré.

O fato de a definição de teoria física de Duhem, como representação matemática das leis, coincidir com a de Poincaré, demarcando-as da metafísica, levou os intérpretes, particularmente Worral, a aliar a concepção de Duhem ao convencionalismo/pragmatismo de Poincaré. O erro dos intérpretes de Duhem foi de terem permanecido no nível da definição da teoria física, e inventado, a partir daí, a interpretação-padrão de Duhem como convencionalista. $\mathrm{O}$ erro foi não terem reconstruído a proposta de Duhem de demarcar a física da metafísica, e entendido que o verdadeiro objetivo dessa demarcação era estabelecer sua demarcação com a concepção de Poincaré. E, por isso, seus intérpretes fizeram tabula rasa de sua superestrutura metafísica com suas sofisticadas teses ontológicas, epistemológicas e axiológicas.

Assim, a interpretação-padrão, para a qual Duhem é convencionalista/ pragmatista, é extremamente apressada e demasiado simplificada, desconsiderando o elemento mais importante e interessante da estratégia de Duhem de construir sua concepção da teoria física: a de que ela seja tal que a demarque, sobretudo, da concepçáo convencionalista/pragmatista de Poincaré, restaurando o valor objetivo da teoria física. Dessa forma, a preservação da metafísica, com diferente função da dos clássicos, é crucial.

A diferença principal entre Duhem e Poincaré está no problema do estatuto cognitivo da teoria física, cujas consequências implicam diferentes concepçóes do modelo de escolha racional de teorias físicas. Duhem esclarece sua diferença com os pragmatistas acerca do estatuto cognitivo, ao longo de sua obra, mas, particularmente, na seguinte passagem: 
Separado das diversas escolas pragmatistas acerca do valor da teoria física, não nos colocamos, sob quaisquer circunstâncias, entre seus discípulos. (DUHEM, 1917, p. 156, grifos meus).

O objetivo de demarcação com a concepção de Poincaré pode ser considerado a terceira tese axiológica ou mesmo uma tese suprema da concepção de Duhem. A realização desse fim, contudo, exige a demarcação com a concepção metafísica clássica, determinando uma nova função para a metafísica. Essa estratégia faz com que sua concepção seja um termo médio entre a concepção metafísica e a concepçáo convencionalista/pragmatista. O elementochave para essa caracterização do termo médio é a teoria da convergência para a verdade e uma teoria da dinâmica do desenvolvimento científico. A concepção envolve uma definição de teoria física como representação matemática, típica do convencionalismo, e um elemento metafísico, que é a crença numa teoria ideal. $\mathrm{O}$ meio é a teoria dinâmica do desenvolvimento para alcançar essa teoria ideal.

Duhem deixa clara a identificação de Poincaré com o pragmatismo:

E não são esses prefácios retumbantes acerca dos trabalhos de Maxwell, feitos pelo distinto professor Poincaré da Sorbonne, aqueles que deram origem na França à crítica pragmatista da física, contra a qual M. Rey hoje protesta? (DUHEM, 1974, p. 319).

Essa abordagem pragmatista é vista por Duhem (1900b, p. 251) como uma nova fonte de ceticismo (neoceticismo), incompatível com a tradição racionalista francesa. Duhem faz a defesa dos princípios do racionalismo clássico intelectualista que se encontra no princípio da unidade lógica (PUL) como forma de organizar a teoria e, também, do princípio da testabilidade das teorias físicas que Poincaré estaria traindo, com sua adesão ao (PSTD) de origem inglesa. Para a tradição do racionalismo clássico,

[...] seria absurdo apresentar duas explicaçôes distintas da mesma lei e sustentar que estas duas explicaçôes podem ser verdadeiras simultaneamente; para um físico inglês, não haveria qualquer contradição no fato de que a mesma lei pudesse ser representada de duas maneiras diferentes através de dois modelos distintos. (DUHEM, 1893c, p. 360). 
Duhem reconhece que, para evitar essas consequências epistemológicas de Poincaré, é preciso recorrer a uma superestrutura metafísica do conhecimento, na forma de uma moldura com os contornos epistemológicos, ontológicos e axiológicos, os quais dão origem a uma concepção normativa da ciência. O único modo de evitar a concepção convencionalista/instrumentalista é por meio de uma concepção normativa da ciência que normatize o comportamento do cientista. Popper não é original em sua proposta, pois essa é a própria natureza da concepção de Duhem.

Os físicos enquanto físicos, como Maxwell e Poincaré, desconsideram totalmente, em sua proposta de demarcação da física da metafísica, o conjunto de teses metafísicas, objetivos e regras os quais transcendem a análise lógica. Eles se guiam apenas com os instrumentos da análise lógica e do método experimental e, principalmente, procuram refletir naturalmente o fazer da teoria física, da qual, no caso de Maxwell e Poincaré, como defensores de uma visão convencionalista/pragmatista, são os principais protagonistas.

Foi com esse objetivo em mente, uma concepção normativa da ciência que a demarcasse da concepção convencionalista/pragmatista, que Duhem faz a crítica da concepção metafísica da ciência dos clássicos, mas preservando a metafísica como um domínio distinto daquele da física, seguindo aqui a filosofia de Aristóteles, segundo a qual, para diferentes objetos, diferentes métodos, atribuindo-lhe novas funçóes, de modo a utilizá-la em sua estratégia de crítica à concepção do convencionalismo/pragmatismo. Esse objetivo converge para uma síntese da tradição intelectualista com a tradição empirista do conhecimento semelhante àquela empreendida por Kant, no racionalismo clássico.

Um estado final para o conhecimento do mundo como expresso na sua tese ontológica de uma teoria ideal como uma classificação natural das leis físicas (DUHEM, 1893c, p. 368.) é absolutamente estratégico para recompor o valor objetivo da teoria física, ao mesmo tempo em que adota uma postura antidogmática por assumir que nossas teorias têm uma natureza hipotética, devendo ser submetidas aos testes para a escolha de uma teoria sempre melhor, o que nos leva a um compromisso com o aperfeiçoamento sistemático da teoria física a ser conduzido pela teoria dinâmica.

$\mathrm{Na}$ construção de teorias físicas que buscam espelhar sistematicamente a classificação natural das leis empíricas está o valor objetivo da teoria física. Este só pode ser apreendido por meio de uma dinâmica do conhecimento e 
não apenas por uma análise lógica do conhecimento fundada na lógica e no método experimental.

A teoria normativa de Duhem é totalmente de inspiração kantiana, contudo, da parte da metafísica dos costumes, em que há um aperfeiçoamento moral do indivíduo racional pelo processo de tornar a vontade cada vez mais racional e, portanto, comportar-se sempre de acordo com o imperativo categórico, para realizar-se como agente autônomo.

O objetivo de construir uma teoria física com uma natureza dinâmica que a impulsione a sempre buscar um crescimento do conhecimento contínuo, sistemático e racional demanda, da superestrutura metafísica do conhecimento de Duhem, duas novas teses epistemológicas, centrais na operacionalização da metodologia com as quais se oporá ao convencionalismo/pragmatismo, que são o princípio da unidade lógica (DUHEM, 1974, p. 103-104) e a teoria da convergência para a verdade (DUHEM, 1974, p.298).

A tese epistemológica da teoria da convergência da verdade afirma a adesão de Duhem à concepçáo de que a verdade é objetivo da ciência e de que devemos ascender a ela através de um processo de conhecimento indireto, uma vez que o sujeito, ou mesmo o método do conhecimento é falível, na forma de uma convergência. Ela substituiu a teoria da cascata da verdade, dos racionalistas clássicos, a qual é adequada apenas para representar uma concepção dogmática da ciência baseada em princípios absolutos e autoevidentes, elementos completamente incompatíveis com a nova imagem da física descrita pelo seu desenvolvimento dinâmico e histórico. Essa tese encontra sua formulação em Duhem: "À medida que a teoria física progride ela se tornar cada vez mais similar a uma classificação natural, que é seu fim ideal” (DUHEM, 1974, p. 298).

Com o uso da metodologia da teoria da ciência (MTC), reconstruímos a superestrutura metafísica do conhecimento, que forma a moldura metateórica de Duhem, com a qual deve ser construída sua teoria da física, o que nos permitiu interpretar Duhem como comprometido com uma concepção realista, por conseguinte, distinta daquela de Poincaré. A metodologia da teoria da ciência (MTC), nesse ponto, instrui-nos a reconstruir sua lógica da ciência, em que estão descritos os instrumentos metodológicos para operacionalizar a sua concepção normativa de ciência de tal sorte que a faça se aproximar sistemática, contínua e racionalmente da teoria ideal, concebida como uma classificação natural das leis empíricas. A ligação entre a metafísica do conhe- 
cimento de Duhem e sua lógica da ciência, para que esta se transforme num protocolo para operacionalizar sua concepção, é dada por uma tese que denomino tese metodológica epistemológica (TME). Nas palavras de Duhem, foi formulada da seguinte maneira:

Portanto, todos aqueles que são capazes de refletir, e que têm consciência de seus próprios pensamentos, sentem em si mesmos uma aspiração, impossível de reprimir, em direção à unidade lógica da teoria física. Esta aspiraçāo em direçâo a uma teoria cujas partes concordam logicamente umas com as outras é, além disso, a acompanhante inseparável daquela outra aspiração, cujo poder irresistível verificamos anteriormente, em direção a uma teoria que é uma classificação natural das leis físicas. Com efeito, sentimos que se as relaçóes reais das coisas, embora não possam ser apreendidas pelos métodos usados pelo físico, são refletidas de algum modo em nossas teorias físicas, esta reflexão não pode ser isenta de ordem ou unidade. (DUHEM, 1974, p. 103-104, grifos meus).

Com essa tese (TME), faz-se a conexão epistemológica, requerida para desenvolver um protocolo de operacionalização de uma concepção normativa, entre a superestrutura metafísica com sua proposta axiológica da realização de uma teoria física ideal e a teoria física real. A aplicação do princípio da unidade lógica, na teoria física real, é o primeiro instrumento metodológico pelo qual se procura fazer a teoria física se aproximar da teoria ideal enquanto uma classificação natural das leis físicas. O princípio da unidade lógica aparece como uma ideia reguladora para superar as subdeterminaçóes e garantir que a teoria física ascenda a uma teoria ideal, a qual deve ser única, portanto, com valor objetivo, como condiçâo para representar a realidade da natureza. A ideia reguladora é aquela da segunda tese axiológica, segundo a qual a teoria dinâmica do crescimento científico deve promover um progresso gradual e contínuo da teoria física para a teoria ideal (DUHEM, 1974, p.298). O propósito dessa tese axiológica é garantir um valor objetivo para a teoria física como um realismo estrutural e convergente (CHIAPPIN, 1989, seção 3.8).

A aplicação desse princípio da unidade lógica significa exigir da teoria física obediência às propriedades da consistência e ausência de contradiçóes, a fim de que haja uma probabilidade de que possamos nos aproximar sucessivamente da teoria ideal por um processo sistemático, regular, racional e contínuo, que é o significado da teoria da convergência para a verdade. $\mathrm{O}$ princípio da unidade lógica (PUL) (DUHEM, 1974, p. 103-104, p. 293) é um dos princípios do racionalismo clássico e está associado ao núcleo duro da 
racionalidade, para Duhem. Duhem menciona a importância desse princípio e que sua aplicação tem justificativa em razóes estranhas à física, ou seja, que está numa superestrutura metafísica, como ele a constrói:

Entre um número de teses postuladas [autorizadas somente por razóes estranhas à física], encontra-se a seguinte: a teoria física deve tentar representar todo grupo de leis naturais através de um único sistema, cujas partes são logicamente compatíveis entre si. (DUHEM, 1974, p. 293).

Esse sistema de teses, objetivos e regras que reconstruímos como superestrutura metafísica de sua teoria da ciência faz dela um verdadeiro termo médio (middle ground) entre a concepção metafísica e a concepção pragmatista/ empirista de Poincaré. Duhem declara seu compromisso de desenvolver essa concepção de termo médio:

Assim, afirmando que a física matemática não é a explicação do mundo material, mas uma simples representação das leis descobertas pela experiência, evitamos a obrigaçáo de declarar verdadeira, para cada ordem dos fenômenos, uma teoria com a exclusão de todas as demais. Mas não somos condenados por isto a adotar todas as teorias, logicamente constituídas, de um mesmo conjunto de leis: temos, para escolher entre elas, regras bastante seguras que, com freqüência, nos permitem preferir razoavelmente uma entre todas as outras. (DUHEM, 1892, p. 170).

Duhem é explícito, ao garantir que, com sua definição de teoria física como representaçáo matemática das leis empíricas, ele evita a concepção de uma explicação metafísica dos fenômenos, porque "[...] evita a obrigação de declarar verdadeira, para cada ordem dos fenômenos, uma teoria com a exclusão de todas as demais", mas, por outro lado, ele não pretende, como faz Poincaré, assumir o princípio da subdeterminação da teoria pelos dados (PSTD) como o princípio metodológico das teorias da física, de maneira a considerar que é equivalente "[...] adotar todas as teorias, logicamente constituídas, de um mesmo conjunto de leis”. Segundo Duhem, devemos ainda evitar a aplicação do princípio da subdeterminação dos dados à teoria física (PSTD), substituindo-o pelo princípio da unidade lógica (PUL), o que exige a construção de um método de escolha racional de teorias, ou seja, o que exige, para "[...] escolher entre elas, regras bastante seguras que, com frequência, nos permitem preferir razoavelmente uma entre todas as outras" (DUHEM, 1915, p. 29; 1892, p. 167; 1895b, p. 393; 1892, p. 170). E, além disso, garantir que 
essa teoria tem mais chance de se aproximar da teoria ideal do que as demais. Assim, uma das características do método de escolha de Duhem é de que ele contenha elementos extralógicos, para além da análise lógica e do método experimental, trazendo com ela um novo modelo de racionalidade. Essa nova concepção de racionalidade deverá supostamente reproduzir de modo mais fiel o processo de tomada de decisão envolvido na ciência, visto que pretende ser uma reconstrução do que fornece a própria história da ciência.

Por conseguinte, se, por um lado, a teoria da ciência de Duhem é desenvolvida para legitimar o princípio da unidade lógica (PUL), por outro, ela preserva a ideia de que a aplicação da regra da subdeterminação em teoria física, ao invés da unidade lógica, é logicamente possível. Daí ser sua concepção da ciência normativa, e seu método de escolher incorporar regras e elementos extralógicos. A concepção de ciência de Duhem assume que a aplicação em teoria física da subdeterminação da teoria pelos dados (PSTD), como quer Poincaré, não envolve qualquer violação dos princípios lógicos.

Do ponto de vista do modelo da concepção metafísica intrínseco ao intelectualismo clássico, a aplicação desse princípio da subdeterminação é interpretada como um absurdo, uma violação dos princípios lógicos da racionalidade (DUHEM, 1893c, p. 360).

A discussão sobre a ilegitimidade da aplicação do princípio da subdeterminação na construção da teoria física requer um novo modelo de racionalidade diferente dos modelos propostos, tanto pela concepção metafísica quanto pela concepção convencionalista/pragmatista e uma nova fonte de legitimidade. Essa legitimidade virá de um outro componente da teoria da ciência de Duhem, a história da ciência. A história da ciência substitui a metafísica como recurso para proporcionar legitimidade à lógica da ciência e à superestrutura metafísica.

A concepção pragmatista/empirista interpreta, com seu modelo mitigado de escolha racional, a aplicação do princípio da subdeterminação em teoria física (PSTF) como legítima, apoiada em uma perspectiva puramente lógica e empírica e nas evidências provenientes da plêiade de indeterminaçôes, modelos formados de massas invisíveis em movimento, que emergiram com a ciência moderna, principalmente dos sistemas dinâmicos, desenvolvidos pelo próprio Poincaré. 
Poincaré acrescenta que esse princípio da subdeterminação explica o uso, na história da ciência, de modelos científicos incompatíveis para a mesma base empírica, e decreta que não há experimentos cruciais. Ele observa:

Isto que precedeu [a regra da subdeterminação] é confirmado pela história de todas as partes da física; em ótica, por exemplo, Fresnel acredita que a vibraçáo seja perpendicular ao plano de polarizaçáo; Neumann considera paralela a este plano. Há muito tempo, busca-se um experimentum crucis que permita decidir entre as duas teorias, mas este náo pôde ser encontrado. (POINCARÉ, 1901, p. viii).

Diferentemente, Duhem argumenta que, se a lógica e o método empírico não possuem poder para legitimar a aplicação nem do princípio da subdeterminação da teoria pelos dados (PSTD) nem do princípio da unidade lógica (PUL), em teoria física, há, entrementes, muitas razóes distintas das puramente lógicas e empíricas, que nos permitem tomar decisōes racionais. Tais decisôes contêm consideraçóes lógicas e empíricas, mas não se reduzem a elas:

Não podemos, portanto, se invocamos exclusivamente razóes de ordem lógica, condenar a incoerência lógica em física teórica. Mas as razóes de ordem puramente lógica não são as únicas que dirigem racionalmente nosso juízo; o princípio de contradição não é o único ao qual nos é permitido recorrer. (DUHEM, 1893c, p. 367).

Essa passagem enfatiza que ele propóe uma nova abordagem da racionalidade, portanto, uma nova teoria da escolha racional (CHIAPPIN, 1989, 2013), um novo meio para avaliar e escolher criticamente teorias científicas. Como já afirmei, o conceito de legitimidade é baseado num sistema de valores, objetivos, padróes, teses e meios, e é examinado em termos da adequação dos meios para atingir os fins propostos. Assim, trata-se de uma decisão metodológica e de um juízo de valor. Essa decisão, todavia, deve levar em conta os princípios axiológicos colocados por cada teoria específica da ciência. Além disso, tais princípios se encontram sujeitos às restriçôes propiciadas pelas teses ontológicas e epistemológicas.

Na concepçáo de Duhem, a aplicação do princípio da unidade lógica é legítima e a aplicaçáo do princípio da subdeterminação da teoria pelos dados (PSTD) é ilegítima, não do ponto de vista lógico, mas do ponto de vista de uma teoria normativa da ciência comprometida com a verdade, por isso, ilegítima do ponto de vista axiológico, dos valores que pretende defender e 
também do ponto de vista da história da ciência. A história da ciência, para Duhem, substitui a metafísica nessa função legitimadora.

O princípio da unidade lógica é a melhor escolha e o princípio mais adequado para satisfazer o objetivo de fazer a teoria física se aproximar sistemática, contínua e racionalmente de uma teoria ideal. Todavia, a exigência é normativa: é uma questão de valores e não de lógica, nem de método experimental que os cientistas busquem sistemas amplos os quais incorporem os anteriores. Mas, segundo Duhem, a história da ciência é capaz de legitimar esses valores e esses princípios, e também regras de escolhas.

A continuidade da teoria da dinâmica do crescimento científico é operacionalizada pelo critério de Duhem da melhor teoria na situação em que duas teorias são confrontadas entre si e com a experiência. $\mathrm{O}$ modelo de racionalidade da teoria dinâmica é operacionalizado por uma teoria metodológica da escolha em substituição a uma teoria lógica da escolha. Uma teoria é melhor que uma rival, se (1) explicar os fatos já conhecidos, bem como (2) aqueles que não eram explicados pela anterior (DUHEM, 1895, p. 392).

A exigência principal é sempre de uma maior amplitude, no sentido de que a melhor teoria tem de representar todas as leis empíricas que a anterior representou e, além disso, representar aquela lei ou aquelas leis que a anterior não conseguiu incorporar, na sua representação. Há progresso, quando a nova teoria incorpora a parte representativa da anterior e ainda aquilo que a anterior não conseguiu incorporar.

A sua metodologia da escolha racional (CHIAPPIN, 1989, cap. 3) tem igualmente, como princípio, que o método experimental é passível de decidir entre teorias, porém, não entre proposiçóes, de modo conclusivo, em termos metodológicos, pela falsidade de uma teoria, mas não pela verdade. Assim, o método experimental pode refutar teorias, mas, tecnicamente, não pode rejeitar. A rejeição de teorias refutadas é atribuída a elementos extralógicos associados ao comportamento do cientista.

Duhem, contrariamente a Poincaré, adota o princípio da testabilidade das teorias físicas dos clássicos, conduzindo por seus pressupostos ontológicos, epistemológicos e axiológicos os quais definem uma teoria dinâmica do conhecimento. No entanto, faz alteraçốes e limitaçóes profundas na natureza da interpretação do princípio da testabilidade dos racionalistas clássicos. 
A mais importante alteração proposta por Duhem sobre a natureza da interpretação dos testes empíricos ficou conhecida como a Tese D (D-thesis) (QUINN, 1969) e afirma uma limitação da testabilidade segundo a qual só podemos testar a teoria como um todo, e não separadamente suas hipóteses, rejeitando a tese do racionalismo clássico da separabilidade e testabilidade de hipóteses isoladas.

No entender de Duhem, a Tese D é uma consequência de suas outras teses epistemológicas (DUHEM, 1917, p. 153; CHIAPPIN, 1989). Essa Tese $\mathrm{D}$ fornece também uma interpretação da base empírica muito próxima àquela de Popper, exceto que Duhem não chega a interpretá-la completamente como uma convenção. Para Duhem, a tese D, afirma que

[...] buscar separar cada hipótese da física teórica das demais pressuposições sobre as quais esta ciência repousa, de modo a sujeitá-la isoladamente ao teste observacional, é buscar uma quimera. (DUHEM, 1974, p. 200).

A interpretação (Tese D) da relação entre teorias rivais e experimentos é também iluminada pela mudança sutil, mas extremamente decisiva, que Duhem realiza na interpretação que Poincaré oferece dos experimentos cruciais. Poincaré (1891, p. 325) sugere que estes não existem. Duhem concorda com Poincaré, porém, apenas quanto ao fato de que o método experimental não pode nem refutar nem confirmar hipóteses, e nem confirmar a teoria física. Todavia, o método experimental pode refutar teorias. Como mencionado, a rejeição de teorias refutadas demanda os elementos extralógicos que vão ser instruídos pela história da ciência dará origem à regra lógico-histórica de que só rejeitamos uma teoria se existir uma outra para substituí-la. Essa regra expressa claramente o papel da história da ciência, tanto como geradora quanto legitimadora dos elementos extralógicos. O papel da história como fonte heurística e legitimadora de elementos extralógicos é uma das características da teoria da ciência de Duhem.

Assim, a construção de uma metodologia de escolha de teorias físicas, central para desenvolver sua concepção realista da teoria física e demarcá-la da concepção de Poincaré, converge para uma sofisticada teoria da escolha racional (CHIAPPIN, 1989), capaz de escolher a melhor teoria entre as teorias rivais em competição para formar a sucessão.

A sucessão dessas teorias físicas escolhidas deve ir revelando (CHIAPPIN, 1989, cap. 2) as características de uma classificação das leis (DUHEM, 
1974, p.24), na forma de um realismo estrutural cada vez mais abrangente e convergente para a teoria ideal que representa essa classificação como classificação natural das leis empíricas (CHIAPPIN, 1989, caps. 2-3, seção 3.8; DUHEM, 1974, p. 26-27). A história da ascensão da mecânica lagrangeana, no lugar da mecânica vetorial, e, posteriormente, substituída pela mecânica hamiltoniana, poderia ser uma ilustração do modelo de realismo estrutural e convergente de Duhem. Arnold (1980) defende que a mecânica hamiltoniana incorpora a mecânica lagrangeana, a qual, por sua vez, incorpora a mecânica newtoniana.

A lógica da ciência combinada com a teoria da convergência da verdade e a teoria física ideal como um realismo estrutural constituem uma importante proposta de uma teoria normativa do progresso para os futuros filósofos da ciência, como Popper (1968; 1983), Kuhn (1992) e Lakatos (1970). A sucessão de teorias é aquela de estruturas mais amplas, contendo estruturas menos amplas, exemplificada com a mecânica analítica e a mecânica newtoniana, como seu caso particular. Aparentemente, Worral (1989) se baseou mais em Duhem do que em Poincaré, pois nada há em Poincaré que sustente epistemologicamente e metodologicamente essa concepção de um realismo estrutural como o melhor de dois mundos que, como mostrei, se relaciona com o racionalismo clássico e com o convencionalismo, numa concepção como um termo médio. Isto não existe em Poincaré. Defendi essa tese sobre Duhem (CHIAPPIN, 1989) antes de aparecer o artigo de Worral, que, na época, foi meu ponto de partida, porque afirmava que Duhem era um convencionalista assim como Poincaré (WORRAL, 1982). Duhem explicitamente formula a insuficiência da abordagem pragmática para dar conta da ordem teórica na qual a própria teoria física se encontra organizada. Com efeito, destaca Duhem:

[...] a ordem segundo a qual a teoria arranja os resultados da observaçáo não encontra sua justificação completa e adequada em suas características práticas ou estéticas. (DUHEM, 1974, p. 335).

Consequentemente, a ordem na qual se organizam as leis empíricas requer uma justificaçâo que transcenda as virtudes práticas e estéticas da teoria física, todavia, o pragmatismo não pode proporcionar tal justificação, por se encontrar limitado à lógica e ao método empírico. Essa ordem não apenas se conecta à classificação das leis empíricas (conhecimento pragmático), mas também à classificação natural (conhecimento teórico) por onde Duhem recupera o valor objetivo da ciência (DUHEM, 1974, p. 26-27, p. 314, p. 330). 
Eis o realismo estrutural e convergente de Duhem (CHIAPPIN, 1989, cap. 3) que ele também chama de um realismo lógico, por oposição ao realismo ilógico, realismo de partículas e entidades, o qual ele denuncia dos racionalistas clássicos. Com a elaboração do realismo estrutural e convergente, Duhem definitivamente completa sua proposta de desenvolver uma concepção da ciência que o demarque da concepção convencionalista/pragmatista de Poincaré.

CHIAPPIN, J. R. N. The Dynamical Theory of Knowledge in Duhem: a Middle Way Between the Classical Conception of Science and the Conventionalist/Pragmatist Conception (POINCARÉ).Trans/Form/Ação, Marília, v. 37, n. 2, p. 57-90, Maio/Ago., 2014.

\begin{abstract}
Using the resources of the methodology of theory of science we propose a rational reconstruction of Duhem's conception of science, interpreting it as a normative theory of the dynamics of knowledge. Such a reconstruction helps to establish that Duhem cannot be classified as a conventionalist/pragmatist as proposed in the standard interpretation, and, furthermore, that Duhem proposes to construct a conception of science as a middle way between a classical metaphysical conception and a conventionalist/pragmatist conception. The methodological strategy for this middle way is the proposal of a structural and convergent realism. Duhem replaces the transcendental subject of the classics with a transcendental theory to be reached by a dynamic process.
\end{abstract}

KEYWORDS: Methodology of theory of science. Dynamic theory of knowledge. Duhem. Poincaré. Structural and convergent realism.

\title{
REFERÊNCIAS
}

ARNOLD, V.I. Mathematical method of classical mechanics. New York: Springer, 1980.

CARTWRIGHT, N. How the laws of physics lie. New York: Clarendon Press, 1984.

CHIAPPIN, J.R.N. Duhem's theory of science: the interplay between Philosophy and history of science. 1989. 388f. Thesis (Ph.D) - University of Pittsburgh, U.S.A., 1989.

- Racionalidade, decisão, solução de problemas e o programa racionalista. Ciência e Filosofia, n. 5, p. 155-219, 1996.

; LEISTER, C. Uma reconstrução racional do programa de pesquisa do racionalismo neoclássico: os subprogramas do convencionalismo/pragmatism (Poincaré) e do realismo estrutural e convergente (Duhem). Trans/form/ação, v. 34, n. 2, p.103-134, 2011.

DESCARTES, R. Meditaçóes metafísicas. São Paulo: Abril Cultural, 1973.

. Regras para a direção do espírito. São Paulo: Martins Fontes, 2012.

DUHEM, P. Leçons sur l'électricité et le magnétisme T.I. Paris: Gauthier-Villars et Fils, 1891. 
Quelques réflexions au sujet des théories physiques. Revue des Questions Scientifiques, v. 31, p.139-177, 1892.

. Une nouvelle théorie du monde inorganique. Revue des Questions Scientifiques, v. 33, p.90-133, 1893a.

. Physique et métaphysique. Revue des Questions Scientifiques, v. 34, p.55-83, 1893 b.

. L'École Anglaise et les théories physiques, à propos d'un livre de W. Thompson. Revue des Questions Scientifiques, v. 34, p.345-378, 1893c.

Fragments d'un cours d'optique - Deuxième fragment: coup d'oeil sur l'optique ancienne. L'optique de Young. Annales de la Société Scientifique de Bruxelles, v. 19, p.27-94, $1895 a$.

. Les Théories de la chaleur-II: les créateurs de la thermodynamique. Revue des Deux Mondes, v. 130, p.380-415, 1895 b.

. Théorie et pratique. Revue Philomathique de Bordeaux et du Sud-Ouest, p.250-262, 1900.

. La Science Allemande. Paris: A. Hermann et fils, 1915.

. Notice sur les titre et travaux scientifiques de Pierre Duhem. Paris: Gauthier-Villars, 1917.

. The aim and structure of physical theory. New York: Atheneum Press, 1974.

. Evolution of mechanics. The Netherlands: Sijthoff \& Noordhoff, 1980.

GIEDYMIN, J. Science and convention: essays on Henri Poincaré's philosophy of science and the conventionalist tradition. New York: Pergamon Press, 1982.

HESSE, M. Duhem, Quine and a New Empiricism. In: MORICK, H. (Ed.). Challenges to empiricism. Indianapolis: Hackett, 1980.

KUHN, T. A Estrutura das revoluções cientificas. São Paulo: Perspectiva, 1992.

LATSIS, S.J. A research programme in economics. In: LATSIS, S.J. (Ed.). Method and appraisal in economics. Cambridge: Cambridge University Press, 1976.

LAKATOS, I. Falsification and the methodology of scientific research program. In: LAKATOS, I; MUSGRAVE, A. (Eds.). Criticism and growth of knowledge. Cambridge: Cambridge University Press. 1970. p. 91-195.

LAUDAN, L. Science and values: the aims of science and their role in scientific debate. Berkeley, CA: University of California Press, 1984.

MCMULLIN, E. Duhem's middle way. Synthese, v. 83, n. 3, p. 421-430, 1990.

PARETO, V. Manuel d'economie politique. Paris: V. Giard et E. Briere, 1909.

POINCARÉ, H. Sur l'expérience de M. Wiener. Comptes Rendus des Séances de l'Academie des Sciences, v. 112, p.325-329, 1891. 
Électricite et optique: la lumière et les théories electrodynamiques. Leçons professeés à la Sorbonne en 1888 et 1899. Paris: Gauthier-Villars, 1901. Science and method. New York: Dover, 1952.

POPPER, K. The Logic of scientific discovery. New York: Harper Torchbooks, 1968. Realism and the aim of science. Totowa, NJ: Rowman and Littlefield, 1983.

PUTNAM, H. Reason, method and history. Cambridge: Cambridge University Press, 1981. QUINN, P. The status of the D-Thesis. Philosophy of Science, v. 36, n. 4, p.381-399, Dec. 1969.

VAN FRAASSEN, B. The Scientific image. New York: Oxford University Press, 1980.

WORRAL, J. Scientific Realism and Scientific change. Philosophical Quarterly, v. 32, n. 128, p.201-231, July, 1982.

. Structural realism: the best of both worlds? Dialectica, v. 43, n. 1/2, p. 99-124, 1989.

Recebido em: 18/01/14

Aceito em: 16/03/14 
CHIAPPIN, J. R. N. 